\title{
Nefroblastoma quístico parcialmente diferenciado
}

\author{
Manuel Bernal B. ${ }^{1}$; Cecilia Castillo T.' ; Elena Kakarieka W. ${ }^{2}$; \\ Jorge Las Heras $\mathbf{B}^{2}$
}

\section{Cystic partially differentiated nephroblastoma}

\begin{abstract}
The case of a patient with a crstic partially differentiated nephroblastoma (CPDN) is reported. Careful histological study is essential to distinguish CPDN and other types of multicystic kidneys ispecially cystic nephrome or multilocular cyst of the kidney). Because of the rere potential for aggresive behavior of this tumor, nephrectomy alone is the therapy of choice. Howgver, its relationship with Witm's tumor is an indication for a regular clinical follow up.

(Key words: tumors, kidney, cystic partıally differentiated nephroblastoma.)
\end{abstract}

El nefroblastoma quístico parcialmente diferenciado (NQPD) es una lesión tumoral quistica renal que se ubica dentro del espectro de los tumores de Wilms ${ }^{1}$. Este tipo de tumor es muy infrecuente y propio de la infancia, habiéndose reportado en la literatura sólo 18 casos bien documentados hasta febrero de 1989 , con una incidencia aproximada de $2,6 \%$ de los tumores renales primarios en nifosos, ${ }^{i, 2}$. La edad de presentación está entre los 4 y 36 meses de vida, sin preponderancia por sexo ${ }^{1,2}$. Su pronóstico es excelente luego de la nefrectomía simple como único tratamiento.

\section{Caso Clínico}

Lactante varón proveniente de Punta Arenas, sin antecedentes mórbidos de importancia. En control de salud al quinto mes de vida se detectó asimetría de la pared abdominal por protrusión de una masa abdomi-

1. Servicio de Cirugía Pediátrica, Unidad de Urología, Hospital Pauh Jaraquemada.

2. Servicio de Anatomia Patológica, Patología Pediátrica, Hospital Paula Jaraquemada. nal redondeada, lisa, de consistencia firme, no dolorosa, de límites netos, que ocupaba la fosa renal y el flanco derecho hasta la cresta ilíaca, sin sobrepasar la línea meáa. No tenía otras manifestaciones. El estudio de laboratorjo mostró indemnidad de la función renal; hemograma y VHS nomales. En el sedimento urinario había hemoglobina, 3 a 4 glóbulos rojos y 2 a 4 glóbulos blancos por campo. La radiografía de tórax era nomal y la de abdomen simple mostraba una opacidad redon. deada, de densidad líquida, homogénea, sin calcificaciones, en el hemiabdomen derecho, que desplaza el aire intestinal hacia la izquierda. En la pielografía endovenosa el aspecto del riñón izquierdo cra normal, $y$ en lado derecho había retardo en la excreción del medio radio opaco, con distorsión del sistema pielocaliciario, sugiriendo un tumor intrarrenal que elongaba $y$ separaba los sistemas calicilares. No había hidonefrosis. No se logró determirar con precisión los límites renales. La ultrasonografía mostraba una lesión rena] en el hado derecho, compuesta por múltiples quistes de tamaño variable, desde muy pequeños hasta $8 \mathrm{~cm}$ el mayor, no comunicados entre ellos. Había evidencia de parénquima renal de ecogenjcidad nomal desplazado hacia ambos polos. La imagen renal izquierda y el hígado eran nomales (figura 1). El nefrograma isotópico indicaba que el riñón izquierdo exa responsable de $72 \%$ de la función renal global. mientras el derecho aportaba los restantes $28 \%$. En el riñón derecho se observaba una zona redondeada, central, que no captaba radiofármaco. 


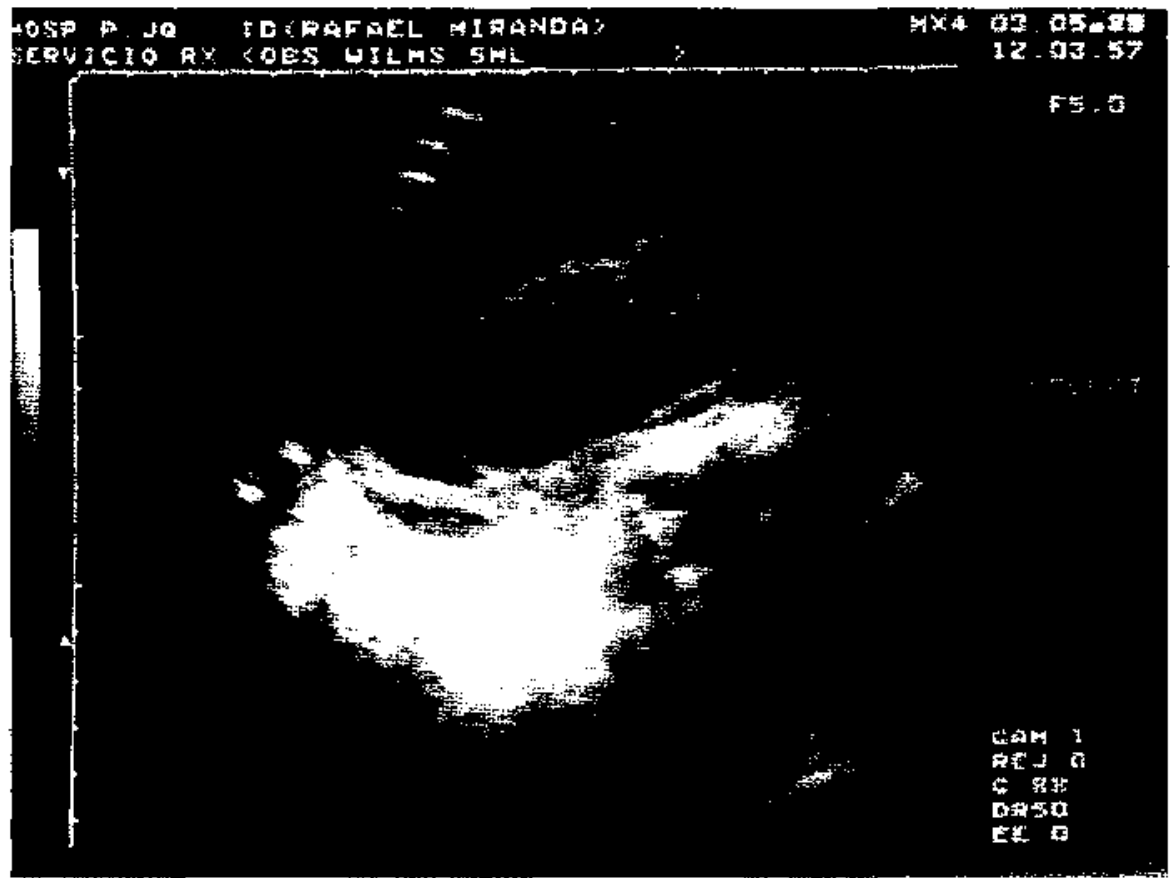

Figura 1: Quiste multiloculado desplazando y comprimiendo el parénquima renal en el estudic ultrasonográfico.

Se practicó nefrouretcrectomía derecha transperitoneal por laparotomía transversa amplia. E1 procedjmiento y la recuperación fueron sin incidentes.

El examen anatomopatológico fue concordante con el estudio ultrasonográfico. F.1 rìnón extirpado pesaba $480 \mathrm{~g}$ y medía $20 \times 10 \times 10 \mathrm{~cm}$. Presentaba una gran masa quística a tensión, bien delimitada y enucleable del parénquima renal, que al corte era multiloculada, con contenido líquido seroso. Los quistes median desde milímetros hasta $6 \mathrm{~cm}$ de diámetro. En uno de cllos se observó una masa papilar solevantada de color pardo de $2 \times 3 \mathrm{~cm}$. Ellos estaban separados por tabiques de variable grosor, en su mayor parte finos (figura 2). Microscópicamente los septos estaban constituidos por mesénquima indiferenciado, constituyendo nódulos blastematosos con estructuras tubulares y estructuras abortivas de glomérulos. Había áreas mixoideas y focos de rabdomioblastos. No se observó cartílago. los quistes estaban revestidos por epitelio cúbico o aplamado. En algunos no hab ta epitelio de revestimiento, siendo reemplazado pos proyecciones papilates de tejido mesenquimático. El parénquima renal circundante no mostraba alteraciones (figura 3).

\section{Comentario}

Las variantes quísticas del nefroblastoma han sido motivo de mucha controversia en la litera. tura. Joshi en $1977^{2}$ definió las características del NQPD, el que anteriomente había recibido múltiples denominaciones como nefroblastoma multiquistico, nefroma quistico multilocular benigno, nefroblastoma poliquistico, nefroblastoma diferenciado, tumor de Wilms quístico y linfangioma quístico ${ }^{1,3}$.

La confusión del NQPD con el quiste renal multilocular se ha debido a la similitud del cuadro clínico y de las imágenes radiológicas y ultrasonográficas, siendo el estudio macro y microscópico del riñón afectado, el único elemento que permite diferenciar ambas entidades ${ }^{1,2}$.

El NQPD es una lesión quistica única y unilateral, de tamaño que varía entre 4,5 y $21 \mathrm{~cm}$ de diámetro mayor, mediana $10 \mathrm{~cm}$. Caracterís. ticamente este quiste es tabicado, conformando una serie de lóculos no comunicados entre $\mathrm{si}^{11}, 2$

La forma de presentación habitual es la que observamos en el caso descrito, con el hallazgo de una masa abdominal palpable como única manifestación. Esta masa puede ser de crecimiento rápido $y$ en ocasiones acompañarse de hematuria, constipación, ir ritabilidad e hipertensión artetial ${ }^{1}$. Los exámenes de laboratorio general son nomales.

Para el estudio y diagnóstico, asi como en cualquier masa abdominal, son fundamentales 


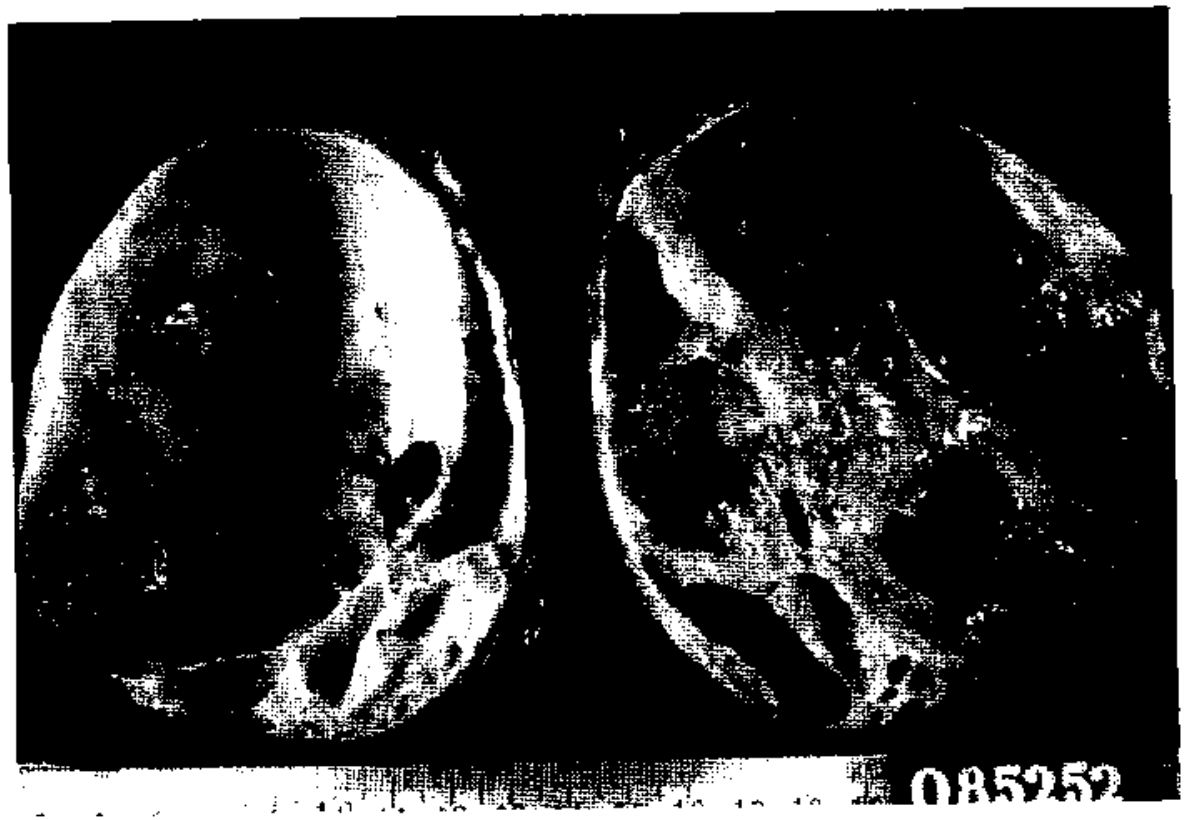

Figuta 2: Pieza operatoria abierta, con un gran quiste tabicado y escaso parénquima renal en anibos polos.

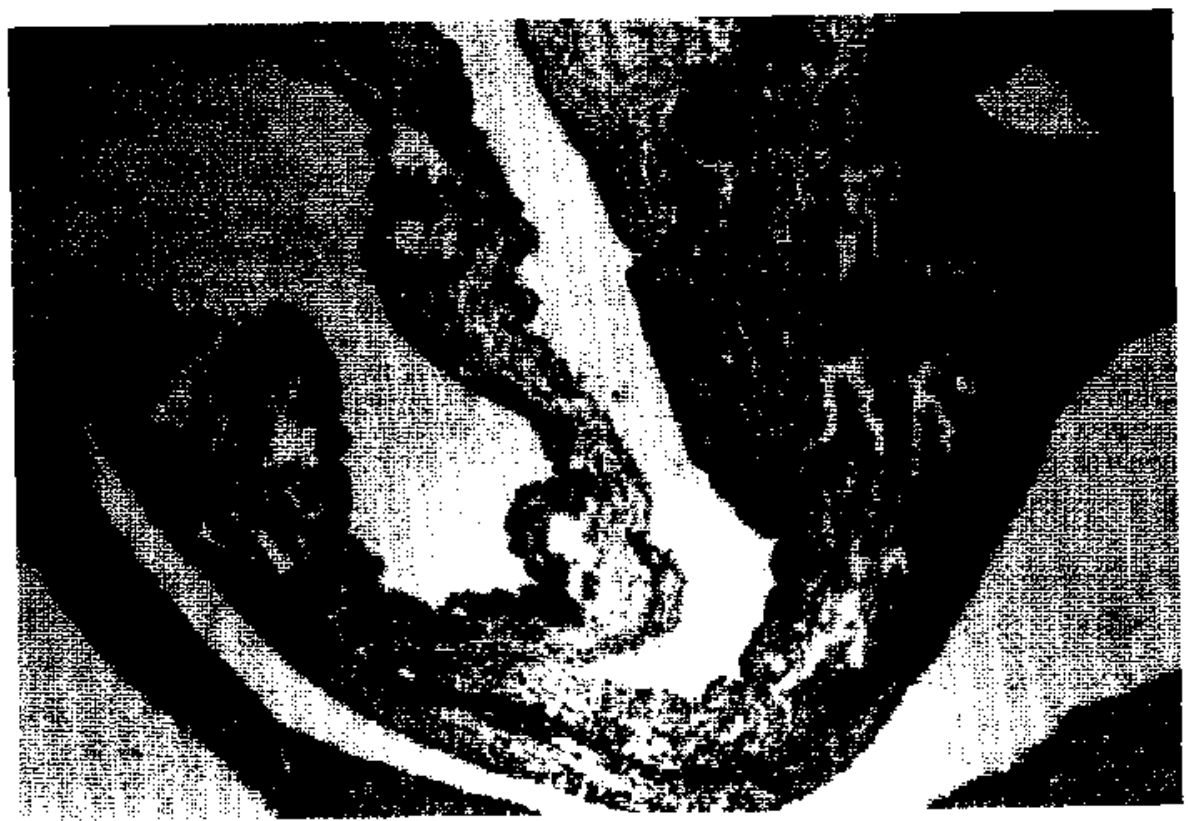

Figura 3: Cavidad quística con proyecciones papilares hacia el lumen. En el estroma, túbulos, cétulas del blastema y mesénquima inmaduro. 
la radiografía simple de abdomen y la pielografía de eliminación, que sugerirân, en este caso, el origen renal de la lesión por distorsión de las imágenes del sistema pielocaliciario, mostrando, además, desplazamiento del parénquína hacia uno o ambos polos e indemnidad del riñón contralateral. La ultrasonografía es la que se acerca más al diagnóstico al descubrir la presencia de una lesión quística renal multiloculada con septos de espesor variable, permitiendo identificar, además, la presencia de parénquima renal de aspecto normal desplazado por el tumor.

En el estudio anatomopatológico, Ja macroscopía corrobora los hallazgos ultrasonográficos de lesión quística bien circunscrita $y$ multiseptada, con contenido líquido seroso o serohemático y desplazamiento del tejido normal. Sin embargo, las modernas técnicas de imágenes no pueden asegurar la benignidad de la lesión renal multiloculada, como tampoco to puede hacer la citología aspirativa ${ }^{4}$, por lo que el diagnóstico definitivo es histológico.

Las características microscópicas de este tumor lo incluyen dentro de las variantes histológicas favorables del tumor de Wilms ${ }^{6}$. Los quistes están tapizados por epitelio cuboidai o plano, mientras en los septos se observa una combinación variable de tejido pobremente diferenciado, que incluye túbulos, glomérulos, mesénquima, músculo esquelético y más infrecuentemente, cartilago. Estos elementos se disponen junto a células del blastema y tejido mesenquimático maduro'.

La patogenia de este tumor no ha sido aclarada. Mientras para algunos autores ésta seria una lesión primariamente tumoral, para otros sería una anomalía del desarrollo o una combinación entre elementos neoplásicos y disgenéticos ${ }^{3}, 3$. También se ha sugerido que el nefroma quístico sería el resultado de la maduración de un NQPD ${ }^{5}$.

El tratamiento de elección es la nefrectomía simple, no habiéndose encontrado beneficio en la adición de quimioterapia o radioterapia. En general, los casos informados en la literatura han tenido sobrevidas excelentes y sólo en un paciente de 4 meses de edad se ha descrito recurrencia local, un año después de la nefrectomía y nuevamente después de 2 años de su primera intervención ${ }^{1,3,7}$.

De lo anteriormente expuesto podemos concluir que la nefrectomia simple es el procedimiento diagnóstico y terapéutico fundamental en el manejo del NQPD, debiendo mantenerse a los pacientes en observación permanente por los eventuales riesgos de recurrencia local.

\section{Resumen}

Se presenta un caso clínico de nefroblastoma quístico parcialmente diferenciado (NQPD), esta. bleciéndose que a pesar de los avances tecnológicos en los métodos no invasivos de diagnóstico, sólo el estudio histopatológico permite la diferenciación con otras lesiones renales quisticas, especialmente con el nefroma quístico o quiste renal multiloculado. La nefrectomía simple es la indicación más adecuada para el diagnóstico y tratamiento del NQPD. La clasificación de esta lesión cono una variedad del tumor de Wilms, obliga a un seguimiento y control estricto de estos pacientes.

(Palabras clave: nefroblastoma quístico parcialmente diferenciado, tumores renaTes.)

\section{Agradecimientos}

Agradecemos la valiosa colaboración del equipo profesional pediátrico del servicio de Radiología del Hospital Paula Jaraquemada.

\section{Referencias}

1. Joshi. V.: Beckrith, J.: Mult ilocular cyst of the Kianey (Cystic Nephroma) and cystic, partially differentiated nephroblastoma. Cancer $1989 ; 64$ : 466-479.

2. Joshi, $V$ : Cystic partially differentiated nephroblastoma: Ar entity in the spectrum of infantile renal neoplasia. Perspect Pediatr Pathol 1979; 5: $217-235$.

3. Igtesias. J.: Panades, M.; Macia, J, Sánchez de Toledo. J.: Mari in, M,; Prats, J.: Nefroblastoma quístico parcialmente diferenciado. An Esp Pediatr 1986;25: 195-199.

4. Alanen, A.: Nurmi, M.: Ekfors. T.: Multilocular senal lesions-A. Diagnostic challenge. Clin Radiol $1987 ; 38: 475 \cdot 477$.

5. Sherman, M.: Siluerman, M:; Balogh, K.; SanGoan Tan, $S_{1}$ : Multilocular tenal cyst. Arch Pathol Lab Med 1987; 111: 732-736.

6. Kromer, S.: Pediatric urologic oncology. Lirol Clin North Am 1985; 12: 31-42.

7. Green, $D .:$ The diagnosis and management of Wilm's tumor. Pediatr Clin North Am 1985; 32 : $735-754$. 